\title{
Reduction of volatile acidity of wines by selected yeast strains
}

\author{
A. Vilela-Moura $\cdot$ D. Schuller $\cdot$ A. Mendes-Faia • \\ M. Côrte-Real
}

Received: 23 April 2008 /Revised: 25 June 2008 / Accepted: 11 July 2008

(C) Springer-Verlag 2008

\begin{abstract}
Herein, we isolate and characterize wine yeasts with the ability to reduce volatile acidity of wines using a refermentation process, which consists in mixing the acidic wine with freshly crushed grapes or musts or, alternatively, in the incubation with the residual marc. From a set of 135 yeast isolates, four strains revealed the ability to use glucose and acetic acid simultaneously. Three of them were identified as Saccharomyces cerevisiae and one as Lachancea thermotolerans. Among nine commercial S. cerevisiae strains, strains S26, S29, and S30 display similar glucose and acetic acid initial simultaneous consumption pattern and were assessed in refermentation assays. In a medium containing an acidic wine with high glucose-low ethanol concentrations, under low oxygen availability, strain S29 is the most efficient one, whereas $L$. thermotolerans $44 \mathrm{C}$ is able to decrease significantly acetic acid similar to the control strain Zygosaccharomyces bailii ISA 1307 but only under aerobic conditions. Conversely, for low glucose-high ethanol concentrations, under aerobic conditions, S26 is the most efficient acid-degrading strain, while under limited-aerobic conditions, all the $S$. cerevisiae strains studied display acetic acid degradation efficiencies identical to Z. bailii. Moreover, S26 strain also reveals capacity to decrease volatile acidity of wines. Together, the S. cerevisiae strains characterized herein appear promising for the oenological removal of volatile acidity of acidic wines.
\end{abstract}

\footnotetext{
A. Vilela-Moura $\cdot$ A. Mendes-Faia

CGB-IBB, Universidade de Trás-os-Montes e Alto Douro,

5001-801 Vila Real, Portugal

D. Schuller • M. Côrte-Real $(\bowtie)$

Centro de Biologia Molecular e Ambiental,

Universidade do Minho,

4710-057 Braga, Portugal

e-mail: mcortereal@bio.uminho.pt
}

Keywords Volatile acidity · Deacidification · Acidic wines . Acidic grape musts $\cdot$ Yeast

\section{Introduction}

Acetic acid is the main component of volatile acidity and is critical for wine quality. Its concentration in wines is approximately $0.5 \mathrm{~g} \mathrm{l}^{-1}$ and must remain below $1.1 \mathrm{~g} \mathrm{l}^{-1}$ according to current legislation. This acid is mainly produced by bacterial spoilage in Botrytis-cinerea-infected grapes. The concentration of acetic acid bacteria can increase drastically on Botrytis-infected grapes (up to $10^{7}$ cells per milliliter, whereas the concentration on healthy grapes ranges usually between $10^{2}$ and $10^{4}$ cells per milliliter). The ruptured grape berry skin, caused by the infection, allows bacteria to access the berry's interior. Usually, Gluconobacter species occur on grapes, but Acetobacter species can dominate on the surface of rotten grapes, using ethanol as preferential carbon source that is produced in small amounts by yeast (Du Toit 2002). Acetic acid can also be formed by yeasts during alcoholic fermentation. Enzymatic reactions that can lead to acetic acid formation in yeast include (1) reversible formation from acetyl coenzyme A (CoA) and acetyl adenylate through acetyl CoA synthetase, (2) cleavage of citrate by citrate lyase, (3) production from pyruvate by pyruvate dehydrogenase, (4) reversible formation from acetyl phosphate by acetyl kinase, and (5) oxidation of acetaldehyde by aldehyde dehydrogenase (Jost and Piendl 1975). Yeast cultures exposed to oxygen, actively synthesizing fatty acids for growth, may produce acetic acid upon entry into anaerobic conditions as a mechanism for the regeneration of free CoA needed for other biosynthetic activities (Boulton et al. 1998). Acetate formation may also play a 
physiological role in the regeneration of reducing equivalents (NADH and NADPH) that are essential for the maintenance of the redox balance (Remize et al. 2000; Saint-Prix et al. 2004). Several other studies have linked the production of acetic acid to increased glycerol production (Englinton et al. 2002; Remize et al. 1999).

Other explanations for the excessive formation of acetic acid during grape must fermentation are, among others, effects derived from nutrient imbalance and competition between coexisting yeasts and bacterial populations during concurrent malolactic fermentations (Boulton et al. 1998).

Sugars are the preferential carbon and energy source of the yeast Saccharomyces cerevisiae, but nonfermentable substrates such as ethanol, glycerol, lactate, or acetate can also be used for the generation of energy and cellular biomass (Schüller 2003). S. cerevisiae is one of the yeast species that can use acetic acid as a sole carbon and energy source. During growth in acetate-containing media, this substrate is metabolized via acetyl CoA formed by one of the two acetyl CoA synthetases: the Acs1p (peroxisomal) and Acs $2 p$ (cytosolic). Acetyl CoA is then consumed in the glyoxylate shunt by isocitrate lyase and malate synthase outside the mitochondria or enters the mitochondria to be oxidized in the tricarboxylic acid cycle. Gluconeogenesis also needs to be active (Dos Santos et al. 2003).

Acetic acid present at the beginning of fermentation is partially metabolized by wine yeasts at the middle-end of this process in the presence of residual sugars (RibéreauGayon et al. 2000). In S. cerevisiae, acetate transport and metabolism are subjected to glucose repression, similar to almost all other nonsugar carbon sources. Hence, growth of $S$. cerevisiae in a medium containing glucose and acetic acid displays a diauxic growth with consumption of acetic acid only after glucose exhaustion (Rodrigues 1998; Casal et al. 1998). This behavior is also described for other yeasts species like Candida utilis (Leão and Van Uden 1986), Torulaspora delbrueckii (Casal and Leão 1995), and Dekkera anomala (Gerós et al. 2000). In contrast, Zygosaccharomyces bailii ISA 1307 displays a biphasic growth in a medium containing a mixture of glucose and acetic acid; the first phase is associated with a simultaneous consumption of glucose and acetic acid and the second with the utilization of the remaining acid (Sousa et al. 1998). These authors propose that both membrane transport and acetyl CoA synthetase and their regulation are important for the ability of $Z$. bailii to metabolize acetic acid in the presence of glucose. These physiological traits are responsible for the species' high resistance in environments containing mixtures of sugars and acetic acid such as those often present during wine fermentation (Sousa et al. 1998). Perfusion experiments also showed that $Z$. bailii is more resistant than $S$. cerevisiae to short-term intracellular $\mathrm{pH}$ changes caused by acetic acid (Arneborg et al. 2000).
Anaerobic growth of $S$. cerevisiae in mixed culture media containing glucose and acetic acid is determined by the extracellular $\mathrm{pH}$ and acetic acid concentration. Without acetic acid, growth is possible at a $\mathrm{pH}$ as low as 2.5, whereas in the presence of $10 \mathrm{~g} \mathrm{l}^{-1}$ of acetic acid the minimum growth-permissive $\mathrm{pH}$ value increased up to 4.5 , and the concentration of the undissociated form should not exceed $5.0 \mathrm{~g} \mathrm{l}^{-1}$ (Mohammad et al. 1997).

Winemakers have been using an empirical biological deacidification procedure to lower acetic acid contents of wines with high volatile acidity (above $0.8 \mathrm{~g} \mathrm{l}^{-1}$ ) and which consists in a refermentation associated to acetic acid consumption by yeasts. According to Ribéreau-Gayon et al. (2000), this enological practice is performed by mixing the acidic wine with freshly crushed grapes or musts in a proportion of no more than $20-30 \%(v / v)$. The initial volatile acidity of this mixture should not exceed $0.6 \mathrm{~g} \mathrm{l}^{-1}$ and the final volatile acidity of the newly made wine rarely exceeds $0.3 \mathrm{~g} \mathrm{l}^{-1}$. The added wine should be microbiologically stable before incorporation to avoid bacterial growth. Alternatively, the acidic wine can be incubated with the residual marc from a finished wine fermentation. Though this practice has been based on the assumption that fermentative yeasts are able to metabolize a large portion of the accumulated acetic acid during an alcoholic fermentation of the first $50-100 \mathrm{~g}$ of sugar (Ribéreau-Gayon et al. 2000), such physiological traits of wine yeasts are generally less well known among enologists. The aim of the present study was to isolate and characterize yeasts species with ability to reduce the acetic acid content of grape musts or wines with high volatile acidity. It is anticipated that the identified yeasts can be used as starters in an efficient and controlled biological procedure to decrease volatile acidity of acidic must or wines.

\section{Materials and methods}

\section{Microorganisms}

From a refermentation process of a wine with excessive acetic acid concentration $\left(1.36 \mathrm{~g} \mathrm{l}^{-1}\right), 135$ yeast isolates were collected. The strains were tested regarding their growth patterns in a differential medium containing glucose $(0.2 \%$ $w / v)$ and acetic acid $\left(5.0 \mathrm{~g} \mathrm{l}^{-1}\right)$, at $\mathrm{pH} 4.0$ or 6.0 (Schuller et al. 2000; data not shown). The strains 43C, 44C, 45C, and $30 \mathrm{C}$ showed both growth and color change of the medium (due to $\mathrm{pH}$ changes), indicating simultaneous glucose and acetic acid consumption. Strain $30 \mathrm{C}$ was collected at the beginning of a refermentation process with the residual marc from a finished wine fermentation. Strains 43C, 44C, and 45C were collected at the end of the same refermentation process.

Several other $S$. cerevisiae commercial strains (S19, S23, S24, S25, S26, S28, S29, S30, and S36) were also tested 
regarding acetic acid and glucose consumption. The mentioned designations (S19-S36) are our internal references in order to avoid revealing commercial names. The strain Z. bailii ISA 1307 was used as a control strain.

Culture media and growth conditions

Strains were kept at $-80^{\circ} \mathrm{C}$ in microtubes containing yeast peptone dextrose (YPD) broth (glucose $2 \% \mathrm{w} / \mathrm{v}$, peptone $1 \% w / v$, yeast extract $0.5 \% w / v)$ supplemented with glycerol $(30 \% v / v)$. Prior to each experiment, strains were streaked onto YPD plates and incubated during $48 \mathrm{~h}$ at $25^{\circ} \mathrm{C}$. Acetic acid utilization was assessed in a minimal mineral medium (Van Uden 1967) containing acetic acid $5.0 \mathrm{~g} \mathrm{l}^{-1}$ and glucose $(0.5 \% \mathrm{w} / \mathrm{v}$ to $5 \% \mathrm{w} / \mathrm{v})$ at $25^{\circ} \mathrm{C}$ and $\mathrm{pH} 3.0$. The medium was then filtered through a membrane (Milipore $0.22-\mu \mathrm{m}$ pore size). A preculture was grown overnight in $10 \mathrm{ml}$ of culture medium, transferred to Erlenmeyer flasks (initial OD of about 0.03 ), and incubated at $25^{\circ} \mathrm{C}$. Acetic acid and glucose consumption was evaluated under aerobic (250-ml Erlenmeyer flask containing $100 \mathrm{ml}$ of minimal medium, $120 \mathrm{rpm})$ and limited-aerobic conditions (250-ml Erlenmeyer flask containing $230 \mathrm{ml}$ of minimal medium, $100 \mathrm{rpm}$ ). In all experiments in liquid media, the flaks were sterilized before use and were only opened to collect the samples in a controlled sterile environment. Commercial $S$. cerevisiae strains were assessed only under limited-aerobic conditions and adjusting acetic acid and glucose concentration to $2.5 \mathrm{~g} \mathrm{l}^{-1}$ and $0.75 \%(w / v)$, respectively. In these assays, the initial concentration of acetic acid was lowered to $2.5 \mathrm{~g} \mathrm{l}^{-1}$ to evaluate the capability of yeasts to decrease maximum volatile acidity levels usually present in acidic spoiled wines and which are about $2.0 \mathrm{~g}^{-1}$.

\section{Refermentation assays}

In order to simulate the refermentation of a wine with excessive amounts of acetic acid, mixtures were prepared containing two thirds of a mineral medium (Van Uden
1967) and one third of acidic white wine. The chemical characteristics of the wines used are summarized in Table 1. Volatile acidity of the mixture was adjusted to $1.13 \mathrm{~g} \mathrm{l}^{-1}$ using glacial acetic acid (Merck) and the $\mathrm{pH}$ of the medium to 3.5 using $\mathrm{NaOH}$. The medium containing wine 1 was further supplemented with glucose $(13 \% \mathrm{w} / \mathrm{v})$ and ethanol $(4 \% v / v)$ in order to simulate the refermentation of a wine with must from the beginning of fermentation. The mineral medium containing wine 2 was supplemented with glucose $(3.3 \% w / v)$ and ethanol $(10 \% v / v)$ in order to simulate the refermentation of a wine with the residual marc from a finished wine fermentation. The mixtures, mineral medium and acidic white wine, were filtered through a membrane (Milipore $0.22-\mu \mathrm{m}$ pore size). Ten milliliter of the inoculated media were incubated overnight and used as a preculture for growth experiments that occurred at $25^{\circ} \mathrm{C}$ under both aerobic and limited-aerobic conditions, as described before. All experiments were performed in triplicate.

Removal of acetic acid from an acidic wine under different oxygenation conditions

Strain S26 was used to assess the influence of aeration on acetic acid removal from an acidic wine (wine 3, Table 1). Volatile acidity was adjusted to $1.44 \mathrm{~g} \mathrm{l}^{-1}$ using glacial acetic acid (Merck) and the pH set to 3.55 using $\mathrm{NaOH}$. The acidic wine was filtered through a membrane (Milipore $0.22-\mu \mathrm{m}$ pore size) prior to use. Ten milliliter of the inoculated wine were incubated overnight and used as a preculture for growth experiments that occurred at $25^{\circ} \mathrm{C}$ under the previously described aerobic and limited-aerobic conditions and also under anaerobic conditions (230-ml acidic wine in a $250-\mathrm{ml}$ Erlenmeyer flask, without mechanical shaking).

Analytical determinations

Cellular growth in liquid media was followed by optical density at $640 \mathrm{~nm}$ in a UV-VIS Scanning Spectrophotometer
Table 1 Chemical characteristics of the wines used in refermentation simulation assays

${ }^{\text {a }}$ CEE N. ${ }^{\circ} 2676 / 90$ - Official Journal of the European Communities, 33, 3.10.1990. (ISSN 0257-7771)

n.d. Not determined

\begin{tabular}{|c|c|c|c|c|}
\hline Chemical characteristics & Wine 1 & Wine 2 & Wine 3 & Analytical methods $\left(\text { CEE N. }{ }^{\circ} 2676 / 90\right)^{a}$ \\
\hline Density at $20^{\circ} \mathrm{C}$ & 0.9940 & 0.9925 & 0.9905 & Densitometry \\
\hline Free $\mathrm{SO}_{2}\left(\mathrm{mg} \mathrm{l}^{-1}\right)$ & 1.92 & 7.04 & 11.9 & Ripper method \\
\hline Total $\mathrm{SO}_{2}\left(\mathrm{mg} \mathrm{l}^{-1}\right)$ & 76.5 & 78.1 & 28.0 & Ripper method \\
\hline $\begin{array}{l}\text { Volatile acidity } \\
\left(\mathrm{g}^{-1} \text { acetic acid }\right)\end{array}$ & 0.51 & 0.54 & 0.36 & $\begin{array}{l}\text { Distillation using a Cazenave-Ferré } \\
\text { followed by titration with phenolphthalein }\end{array}$ \\
\hline Residual sugar $\left(\mathrm{g}^{-1}\right)$ & n.d. & n.d. & 1.10 & Lane-Eynon method \\
\hline $\begin{array}{l}\text { Titratable acidity } \\
\left(\mathrm{g} \mathrm{l}^{-1} \text { tartaric acid }\right)\end{array}$ & 5.13 & 5.17 & 8.89 & Titration with bromothymol blue \\
\hline $\mathrm{pH}$ & 3.17 & 3.22 & 3.01 & Potentiometer \\
\hline $\begin{array}{l}\text { Alcoholic degree }(v / v) \\
\text { ethanol }(\%)\end{array}$ & 11.8 & 11.3 & 10.4 & Distillation \\
\hline
\end{tabular}


(Shimadzu UV-2101PC). Glucose, acetic acid, and ethanol concentrations were determined by high-performance liquid chromatography with a Perkin-Elmer series 10 Liquid Chromatographic System equipped with an ion exclusion, cation exchange column (BIORAD-HPX-87H), and an RI detector. The column was eluted with sulfuric acid $(0.013 \mathrm{~N})$ at $62^{\circ} \mathrm{C}$, at a flow rate of $0.6 \mathrm{ml} \mathrm{min}{ }^{-1}$. Samples were filtered through a membrane (Milipore $0.22-\mu \mathrm{m}$ pore size) prior injection of a volume of $6 \mu \mathrm{l}$. The components were identified by their relative retention times in comparison to the values obtained for the respective standards, using the program JCL 6000 Software (Jones Chromatography). Acetic acid concentration was also determined enzymatically with an Enzytec Laboratories kit.

Analysis of the density, $\mathrm{pH}$, alcohol concentration, volatile acidity, $\mathrm{SO}_{2}$, and titratable acidity was performed according to published methods, outlined in Table 1.

\section{DNA isolation}

Yeast cells were cultivated in 1-ml YPD medium $\left(36 \mathrm{~h}, 28^{\circ} \mathrm{C}\right.$, $160 \mathrm{rpm})$. DNA isolation was performed as described (Lopez et al. 2001) with a modified cell lysis procedure, using $25 \mathrm{U}$ of Zymolase (SIGMA). Cell lysis was dependent on the strain and lasted between $20 \mathrm{~min}$ and $1 \mathrm{~h}\left(37^{\circ} \mathrm{C}\right)$. DNA was used for sequencing and microsatellite analysis.

\section{D1-D2 region amplification and sequencing}

The D1-D2 variable domain at the 5' end of the 26S rDNA (nucleotides 63-642 for S. cerevisiae) was amplified with primers NL-1 (GCATATCAATAAGCGGAGGAAAAG) and NL-4 (GGTCCGTGTTTCAAGACGG; O’Donnell 1993), obtained from MWG Biotech, Germany. Polymerase chain reactions $(\mathrm{PCR})$ were performed in a reaction mixture $(30 \mu \mathrm{l})$ containing 60 -ng genomic DNA, 12 pmol of each primer, $0.2 \mathrm{mM}$ of deoxynucleotide triphosphate (MBI Fermentas), $1.5 \mathrm{mM} \mathrm{MgCl}_{2}, 3 \mu \mathrm{l}$ of $10 \times$ reaction buffer (MBI Fermentas), and $0.6 \mathrm{U}$ of Taq polymerase (MBI Fermentas). Amplification reactions were performed on a BioRad iCycler thermal cycler with the following cycling parameters: initial denaturation at $94^{\circ} \mathrm{C}$ for $4 \mathrm{~min}$, followed by 36 cycles at $94^{\circ} \mathrm{C}$ for $20 \mathrm{~s}, 53^{\circ} \mathrm{C}$ for $20 \mathrm{~s}$, and $72^{\circ} \mathrm{C}$ for $1 \mathrm{~min}$, with a final extension at $72^{\circ} \mathrm{C}$ for $5 \mathrm{~min}$. The amplified fragment was purified (Nucleospin Extract II PCR cleanup kit, Machery-Nagel) and sequenced by using the ABI Big Dye Terminator kit (version 3.1). Processing of the samples for loading onto the sequencer was performed as per manufacturer's instructions. Sequence similarity search was done using GenBank BLASTN search (Altschul et al. 1990).
Microsatellite amplification

Six trinucleotide microsatellite loci (ScAAT1, ScAAT2, ScAAT3, ScAAT4, ScAAT5, and ScAAT6), originally described by Pérez et al. (2001), were used as molecular markers for S. cerevisiae strain delimitation. Their amplification and analysis was performed as previously described (Schuller et al. 2004). PCR products were resolved in an ABI Prism 310 DNA sequencer (Applied Biosystems) and analyzed using the corresponding Genescan software.

\section{Statistical analysis}

A one-way analysis of variance (ANOVA) or singlefactor ANOVA (Excel, Microsoft) and the program STATISTICA (factorial ANOVA) were used to evaluate the differences between the yeasts strains concerning glucose and acetic acid consumption in the different assays.

\section{Results}

Molecular identification and characterization of the isolated wine strains

Strains $30 \mathrm{C}, 43 \mathrm{C}, 44 \mathrm{C}$, and $45 \mathrm{C}$ were identified by the amplification of the D1-D2 variable domain at the 5' end of the 26S rDNA (nucleotides 63-642 for S. cerevisiae) with primers NL-1 and NL-4 (O'Donnell 1993) and the amplified fragments were subsequently sequenced. Sequence similarity search was done using GenBank BLASTN search (Altschul et al. 1990). D1-D2 sequence of strain 30C, 43C, and 45C showed 99-100\% identity with deposited S. cerevisiae sequences (accession numbers U53879, AY130346, and U44806, respectively). D1-D2 sequence of strain $44 \mathrm{C}$ shows $99 \%$ identity with Lachancea thermotolerans NRRL Y-8284 (accession number U69581; Kurtzman 2003; Kurtzman and Robnett 2003). Consulting the Centraalbureau voor Schimmelcultures, this strain is similar to the type strain of Zygosaccharomyces thermotolerans, isolated from mirabelle plum and identified by Lachance (1998). Until October 2004, this species was considered as Kluyveromyces thermotolerans.

Microsatellite analysis (Table 2) shows that $S$. cerevisiae strains $30 \mathrm{C}$ and $45 \mathrm{C}$ are genetically very similar, showing identical alleles for five loci. These two strains could be merely distinguished by locus ScAAT5, being strain 30C homozygous (216 bp) and strain $45 \mathrm{C}$ heterozygous (216 or $219 \mathrm{bp}$ ). 
Table 2 Allelic diversity of $S$. cerevisiae strains 30C, 45C, and 43C

\begin{tabular}{|c|c|c|c|c|c|c|}
\hline \multirow[b]{2}{*}{ Strain number } & \multicolumn{6}{|c|}{ Microsatellite (bp) } \\
\hline & ScAAT1 & ScAAT2 & ScAAT3 & ScAAT4 & ScAAT5 & ScAAT6 \\
\hline $30 \mathrm{C}$ & 171 & 381 & 271 & 329 & 216 & 259 \\
\hline $45 \mathrm{C}$ & 171 & 381 & 271 & 329 & 216 or 219 & 259 \\
\hline $43 \mathrm{C}$ & 158 & 378 & 247 & 308 & 219 & 259 \\
\hline
\end{tabular}

Numbers indicate the length (bp) of alleles for the six microsatellite loci ScAAT1 to ScAAT6

Characterization of the isolated strains regarding their ability to degrade acetic acid

Subsequently, we studied the effects of glucose and acetic acid concentrations and aeration conditions on the consumption of acetic acid by the previously mentioned isolates. The strain Z. bailii ISA1307, previously shown to use acetic acid simultaneously with glucose (Sousa et al. 1998), was used as reference. As shown in Table 3, strains Z. bailii ISA 1307 and L. thermotolerans $44 \mathrm{C}$ revealed as most efficient in consuming acetic acid, being able to degrade $61.6 \%$ and $28.2 \%$ of the initial acid, respectively, when grown under limited-aerobic conditions in a mixed substrate medium containing glucose $(5.0 \% \mathrm{w} / \mathrm{v})$ and acetic acid $\left(5.0 \mathrm{~g} \mathrm{l}^{-1}\right)$. Under limited-aerobic conditions, and for an initial glucose concentration of $0.75 \%(w / v)$, strains $43 \mathrm{C}$ and S26 displayed an identical ability $(P>0.05$, statistical class "b") to degrade acetic acid although not so efficient as strain Z. bailii ISA 1307 (statistical class "a") because they consumed just about $50 \%$ of the acetic acid after $312 \mathrm{~h}$. Strain $44 \mathrm{C}$ has an identical ability to degrade acetic acid in the media with $5.0 \%$ or $0.75 \% \mathrm{w} / \mathrm{v}$ of glucose under limited-aerobic conditions (statistical class "c"). The higher initial concentration of glucose does not alter the rate of acetic acid consumption by strain $44 \mathrm{C}$; however, this strain decreased the rate of glucose consumption (statistical classes "a" and "b"). Only under aerobic conditions and for $0.5 \%(w / v)$ of glucose, all the four isolated strains completely consumed the acetic acid. Even though, regarding the relatedness of the strains in terms of acetic acid consumption, they behaved significantly different $(P \leq 0.05)$ in respect to the time necessary to complete the acid consumption, varying between 72 and 216 h (Z. bailii ISA 1307 and 44C, respectively).

The ability of commercial wine strains to degrade acetic acid

With the purpose to further evaluate whether the ability to degrade acetic acid in the presence of glucose was a characteristic of the isolated strains, nine commercial $S$. cerevisiae strains were chosen for further analysis. These assays were carried out in minimal medium containing acetic acid $2.5 \mathrm{~g} \mathrm{l}^{-1}$ and glucose $0.75 \%(w / v)$, under limited-aerobic conditions, at $25^{\circ} \mathrm{C}$ and $\mathrm{pH}$ 3.0. Strain S26 was the most efficient acetic-acid-consuming strain, leading to values below $0.7 \mathrm{~g} \mathrm{l}^{-1}$ at the end of $168 \mathrm{~h}$ (Fig. 1). Besides, this strain exhausted glucose very quickly. Table 4 shows that the strains display significant differences $(P \leq 0.001)$ regarding acetic acid consumption ability. However, strains S29 and

Table 3 Concentration of acetic acid and glucose $\left(\mathrm{g} \mathrm{l}^{-1}\right)$ present in the minimal media with different initial concentrations of glucose $(0.5 \%$ to $5 \%$ $w / v)$ and acetic acid $\left(5.0 \mathrm{~g}^{-1}\right)$, after fermentation by the four yeast isolates in comparison with S. cerevisiae strains S26 and Z. bailii ISA 1307 , under aerobic $(216 \mathrm{~h})$ or limited-aerobic conditions $(312 \mathrm{~h})$, at $25^{\circ} \mathrm{C}$ and $\mathrm{pH} 3.0$

\begin{tabular}{|c|c|c|c|c|c|c|}
\hline \multirow[t]{3}{*}{ Yeasts strains } & \multicolumn{2}{|c|}{ Aerobic conditions } & \multicolumn{4}{|c|}{ Limited-aerobic conditions } \\
\hline & \multicolumn{2}{|c|}{ Glucose $(0.5 \% w / v)$, acetic acid $\left(5.0 \mathrm{~g} \mathrm{l}^{-1}\right)$} & \multicolumn{2}{|c|}{ Glucose $(0.75 \% w / v)$, acetic acid $\left(5.0 \mathrm{~g}^{-1}\right)$} & \multicolumn{2}{|c|}{ Glucose $(5 \% w / v)$, acetic acid $\left(5.0 \mathrm{~g}^{-1}\right)$} \\
\hline & Glucose $\left(\mathrm{g} \mathrm{l}^{-1}\right)$ & Acetic acid $\left(\mathrm{g} \mathrm{l}^{-1}\right)$ & Glucose $\left(\mathrm{g}^{-1}\right)$ & Acetic acid $\left(\mathrm{g} \mathrm{l}^{-1}\right)$ & Glucose $\left(\mathrm{g} \mathrm{l}^{-1}\right)$ & Acetic acid $\left(\mathrm{g} \mathrm{l}^{-1}\right)$ \\
\hline ISA 1307 & $0 \mathrm{a}$ & $0(72 \mathrm{~h})^{\mathrm{a}} \mathrm{a}$ & $0 \mathrm{a}$ & $0.02 \pm 0.03 \mathrm{a}$ & $0 \mathrm{a}$ & $1.92 \pm 0.03 \mathrm{~b}$ \\
\hline S26 & $0 \mathrm{a}$ & $0(144)^{a}$ a & $0 \mathrm{a}$ & $2.09 \pm 0.09 \mathrm{~b}$ & $0 \mathrm{a}$ & $4.41 \pm 0.03 \mathrm{~d}, \mathrm{e}$ \\
\hline $30 \mathrm{C}$ & $0 \mathrm{a}$ & $0(192 \mathrm{~h})^{\mathrm{a}} \mathrm{a}$ & $0 \mathrm{a}$ & $4.40 \pm 0.04 \mathrm{~b}, \mathrm{e}$ & $0 \mathrm{a}$ & $4.90 \pm 0.04 \mathrm{e}$ \\
\hline $43 \mathrm{C}$ & $0 \mathrm{a}$ & $0(168 \mathrm{~h})^{\mathrm{a}} \mathrm{a}$ & $0 \mathrm{a}$ & $2.02 \pm 0.09 \mathrm{~b}$ & $0 \mathrm{a}$ & $4.77 \pm 0.02 \mathrm{e}$ \\
\hline $44 \mathrm{C}$ & $0 \mathrm{a}$ & $0(216 h)^{a} a$ & $0 \mathrm{a}$ & $3.99 \pm 0.13 \mathrm{c}, \mathrm{d}$ & $15.11 \pm 0.06 \mathrm{~b}$ & $3.59 \pm 0.06 \mathrm{c}$ \\
\hline $45 \mathrm{C}$ & $0 \mathrm{a}$ & $0(168 h)^{a} a$ & $0 \mathrm{a}$ & $4.01 \pm 0.08 \mathrm{c}, \mathrm{d}$ & $0 \mathrm{a}$ & $4.71 \pm 0.01 \mathrm{~d}, \mathrm{e}$ \\
\hline
\end{tabular}

Results obtained for strains and culture conditions with the same letter are not significantly different $(P<0.001)$.

${ }^{a}$ Time needed to exhaust acetic acid from the medium. 
Fig. 1 Acetic acid (squares), glucose (diamonds), and ethanol (triangles) consumption by nine commercial strains and $Z$. bailii ISA 1307 (control strain), in minimal medium containing acetic acid $2.5 \mathrm{~g}^{-1}$ and glucose $0.75 \%(w / v)$, under limited-aerobic conditions, at $25^{\circ} \mathrm{C}$ and $\mathrm{pH}$ 3.0

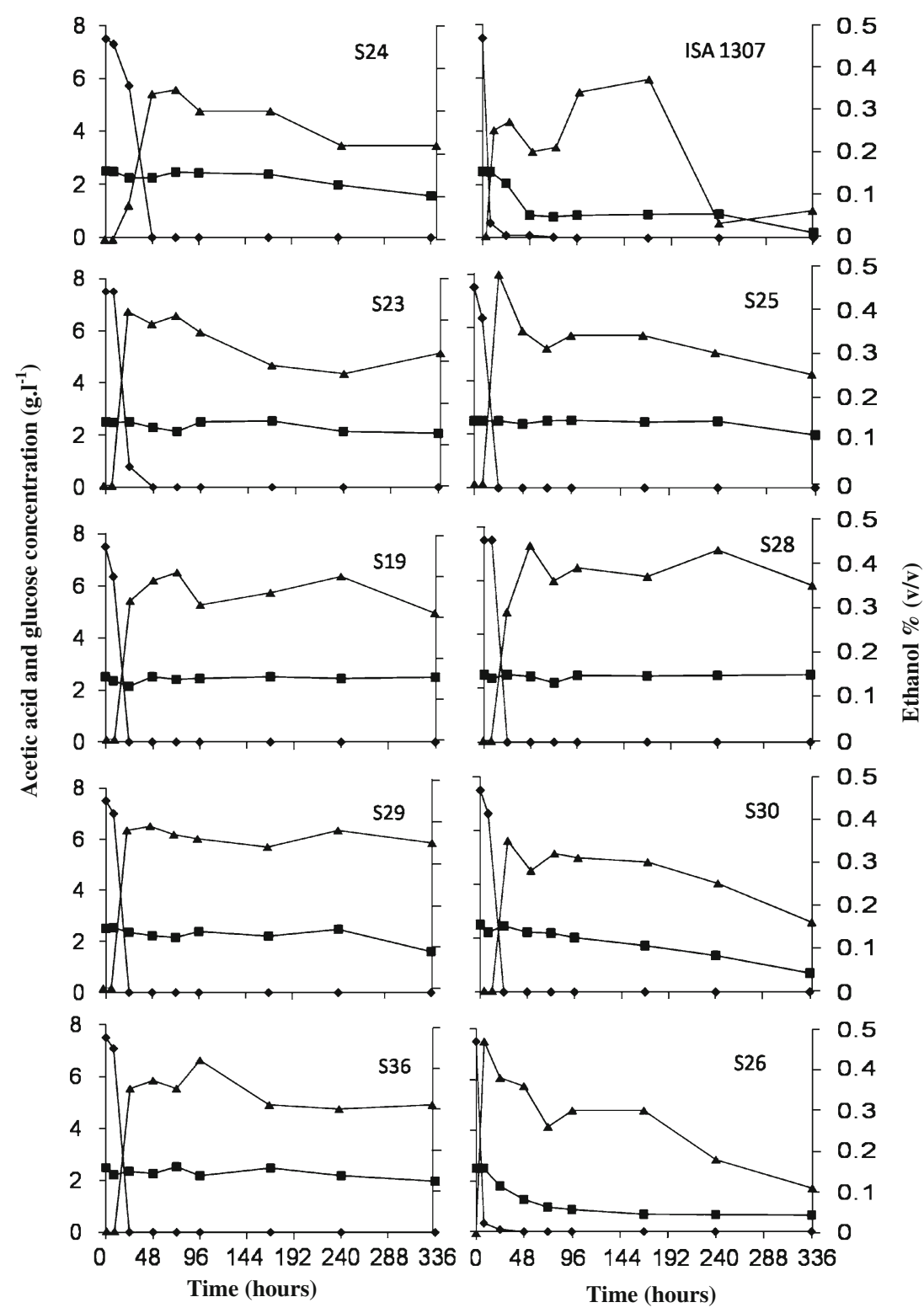

S30 showed the most similar behavior to S26 and therefore were included in the refermentation simulation assays with acidic wines.

\section{Refermentation simulation assays with acidic wines}

As previously shown, both the isolated strains $(43 \mathrm{C}, 45 \mathrm{C}$, and $44 \mathrm{C}$ ) and the commercial S. cerevisiae strains S26, S29, and S30 have demonstrated capacity to remove acetic acid. To verify their potential application in a refermentation process under wine cellar conditions, they were inoculated in a mixed medium containing two thirds of minimal medium (Van Uden 1967) supplemented with one third of an acidic white wine. The volatile acidity of the mixture was $1.13 \mathrm{~g} \mathrm{l}^{-1}$, corresponding to the values usually found in acidic wines. Two wine-supplemented mineral media were tested, according to Table 1; the first medium simulated the refermentation of a wine with fresh crushed grapes or with grape must; the second wine-supplemented mineral medium simulated the refermentation of a wine with the residual marc from a finished wine fermentation. Acetic acid consumption was again evaluated under aerobic or limited-aerobic conditions to assess whether aeration was a limiting factor of the process. We evaluated the rate of acetic acid and glucose consumption at the end of 48 and $72 \mathrm{~h}$ for the first and second medium, respectively (Table 5). Statistical analysis (factorial ANOVA) showed that each strain has a characteristic pattern of glucose and acetic acid consumption $(P \leq 0.001)$ for the four growth conditions tested. Besides, the strains displayed significant differences regarding acetic acid consumption and glucose consumption for each condition tested. Among S. cerevisiae strains, 
except strain S29, the glucose and acetic acid consumption patterns were most similar for limited-aerobic growth conditions (both in high- and low-glucose conditions).

The most efficient strains-conditions regarding acetic acid consumption (letters $g$ and $h$, Table 5) were the two non-Saccharomyces strains $Z$. bailii ISA 1307and $L$. thermotolerans $44 \mathrm{C}$ in the high-glucose medium (aerobic condition), followed by strain S29 in the same medium (limited-aerobic condition), and by strains S26 and ISA1307 in the medium containing glucose $(3.3 \% \mathrm{w} / \mathrm{v})$ and ethanol $(10 \% v / v)$ under aerobic conditions (Table 5). Some of the strains showed intermediate acetic acid removal efficiency (between $8.6 \%$ and $46.8 \%$, statistical classes 'b- $\mathrm{f}$ ") under certain conditions. The lowest acetic acid removal efficiency (statistical class "a") was observed for strains $43 \mathrm{C}, 45 \mathrm{C}$, and S30 (high-glucose-concentration medium, aerobiosis) and for L. thermotolerans 44C (highglucose-concentration medium, limited aerobiosis).

Strains 43C, 45C, S26, and S30 consumed glucose efficiently (removal of $87-100 \%$, statistical class "g") from both culture media under limited-aerobic conditions and from the high-glucose culture medium under aerobic conditions. In this respect, strain S26 was one exception displaying high glucose consumption for both media, and under aerobic and anaerobic conditions. Strains ISA 1307 and $44 \mathrm{C}$ were intermediate to poor glucose consumers in high-glucose medium (aerobic conditions) and the remaining three culture conditions, respectively. A similar pattern, although not so pronounced, was found for strain S29.

Strains 43C, 45C, S26, and S30 showed identical glucose and acetic acid consumption patterns for both media under limited-aerobic conditions. Strains $43 \mathrm{C}$ and $45 \mathrm{C}$ that are genetically highly related (Table 2 ) showed distinct glucose consumption efficiency in the low-glucose medium under aerobic conditions. Taken all together, strain S26 revealed the most desirable combination of glucose and acetic consumption ( $100 \%$ and $86.7 \%$, respectively) when grown in a medium containing low glucose and high ethanol concentrations, under aerobic conditions. Moreover, under limited-aerobic conditions and for both media, strain S26 displayed acid removal efficiencies identical to strain ISA 1307 but associated to higher glucose removal efficiency comparatively with strain ISA 1307.

Removal of acetic acid from an acidic wine under different oxygenation conditions

As previously shown, S. cerevisiae S26 has demonstrated capacity to remove acetic acid under aerobic and limitedaerobic conditions. We further evaluated the capacity of this strain to remove acetic acid from an acidic wine that was not supplemented with glucose (Table 1, wine 3, residual sugar of $1.10 \mathrm{~g}^{-1}$ ) under different oxygen conditions. Acetic acid 
Table 5 Percentage of acetic acid and glucose consumption after refermentation of wine-supplemented culture medium containing glucose $13 \%$ $(w / v)$ and ethanol $4 \%(v / v)$ or glucose $3.3 \%(w / v)$ and ethanol $10 \%(v / v)$, after 48 and $72 \mathrm{~h}$ of incubation, respectively

\begin{tabular}{|c|c|c|c|c|c|}
\hline \multirow[t]{2}{*}{ Yeast strains } & & \multicolumn{2}{|c|}{ Glucose $(13 \% w / v)$ and ethanol $(4 \% v / v)$} & \multicolumn{2}{|c|}{ Glucose $(3.3 \% w / v)$ and ethanol $(10 \% v / v)$} \\
\hline & & Aerobic conditions & Limited-aerobic conditions & Aerobic conditions & Limited-aerobic conditions \\
\hline \multirow[t]{2}{*}{ ISA 1307} & Acetic acid & $94.8 \pm 3.30 \mathrm{~h}$ & $40.9 \pm 9.80 \mathrm{e}, \mathrm{f}$ & $71.2 \pm 3.02 \mathrm{~g}$ & $41.6 \pm 2.64 \mathrm{e}, \mathrm{f}$ \\
\hline & Glucose & $52.4 \pm 2.62 \mathrm{e}, \mathrm{f}$ & $38.8 \pm 6.36 \mathrm{~d}, \mathrm{e}$ & $23.1 \pm 5.60 \mathrm{a}, \mathrm{b}, \mathrm{c}$ & $39.4 \pm 2.10 \mathrm{~d}, \mathrm{e}$ \\
\hline \multirow[t]{2}{*}{$44 \mathrm{C}$} & Acetic acid & $94.6 \pm 4.79 \mathrm{~h}$ & $15.25 \pm 3.30 \mathrm{a}, \mathrm{b}, \mathrm{c}$ & $28.1 \pm 1.70 \mathrm{c}, \mathrm{d}, \mathrm{e}$ & $17.4 \pm 7.16 \mathrm{~b}, \mathrm{c}, \mathrm{d}$ \\
\hline & Glucose & $58.5 \pm 8.60 \mathrm{f}$ & $31.0 \pm 5.69 \mathrm{c}, \mathrm{d}$ & $16,4 \pm 1.76 \mathrm{a}, \mathrm{b}$ & $30.4 \pm 5.79 \mathrm{c}$ \\
\hline \multirow[t]{2}{*}{$43 \mathrm{C}$} & Acetic acid & $0 \pm 0 \mathrm{a}$ & $31.2 \pm 9.70 \mathrm{c}, \mathrm{d}, \mathrm{e}, \mathrm{f}$ & $36.4 \pm 9.88 \mathrm{e}, \mathrm{f}$ & $37.5 \pm 3.17 \mathrm{e}, \mathrm{f}$ \\
\hline & Glucose & $100 \pm 0 \mathrm{~g}$ & $96.94 \pm 3.17 \mathrm{~g}$ & $40.7 \pm 7.42 \mathrm{~d}, \mathrm{e}$ & $100 \pm 0 \mathrm{~g}$ \\
\hline \multirow[t]{2}{*}{$45 \mathrm{C}$} & Acetic acid & $16.0 \pm 4.06 \mathrm{a}, \mathrm{b}, \mathrm{c}$ & $40.3 \pm 6.60 \mathrm{e}, \mathrm{f}$ & $33.4 \pm 6.88 \mathrm{~d}, \mathrm{e}, \mathrm{f}$ & $40.1 \pm 6.58 \mathrm{e}, \mathrm{f}$ \\
\hline & Glucose & $100 \pm 0 \mathrm{~g}$ & $97.4 \pm 2.28 \mathrm{~g}$ & $23.8 \pm 6.61 \mathrm{a}, \mathrm{b}, \mathrm{c}$ & $100 \pm 0 \mathrm{~g}$ \\
\hline \multirow[t]{2}{*}{ S26 } & Acetic acid & $46.8 \pm 4.99 \mathrm{f}$ & $45.9 \pm 5.60 \mathrm{f}$ & $86.7 \pm 2.63 \mathrm{~g}, \mathrm{~h}$ & $44.6 \pm 3.58 \mathrm{e}, \mathrm{f}$ \\
\hline & Glucose & $100 \pm 0 \mathrm{~g}$ & $87.7 \pm 10.72 \mathrm{~g}$ & $100 \pm 0 \mathrm{~g}$ & $100 \pm 0 \mathrm{~g}$ \\
\hline \multirow[t]{2}{*}{ S30 } & Acetic acid & $8.6 \pm 4.44 \mathrm{a}, \mathrm{b}$ & $39.9 \pm 5.70 \mathrm{e}, \mathrm{f}$ & $36.3 \pm 4.91 \mathrm{e}, \mathrm{f}$ & $35.1 \pm 6.37 \mathrm{e}, \mathrm{f}$ \\
\hline & Glucose & $100 \pm 0 \mathrm{~g}$ & $98.2 \pm 3.15 \mathrm{~g}$ & $31.7 \pm 5.40 \mathrm{c}, \mathrm{d}$ & $100 \pm 0 \mathrm{~g}$ \\
\hline \multirow[t]{2}{*}{ S29 } & Acetic acid & $31.4 \pm 2.47 \mathrm{c}, \mathrm{d}, \mathrm{e}, \mathrm{f}$ & $82.5 \pm 3.03 \mathrm{~g}, \mathrm{~h}$ & $9.6 \pm 3.03 \mathrm{a}, \mathrm{b}$ & $43.3 \pm 4.75 \mathrm{e}, \mathrm{f}$ \\
\hline & Glucose & $92.7 \pm 1.15 \mathrm{~g}$ & $56.8 \pm 4.65 \mathrm{f}$ & $17.3 \pm 2.86 \mathrm{a}, \mathrm{b}$ & $14.85 \pm 4.98 \mathrm{a}$ \\
\hline
\end{tabular}

Results obtained for strains and culture conditions with the same letter are not significantly different $(P<0.001)$.

consumption and growth require the presence of oxygen as provided under our limited-aerobic or aerobic experimental setup. The differences between the three culture conditions were statistically significant $(P<0.001)$. As shown in Fig. 2 , maximum growth occurred under aerobic conditions and the consumption of acetic acid was close to $90 \%$ (after $432 \mathrm{~h}$ of incubation), accompanied by a considerable consumption of ethanol. Under limited-aerobic condition, the percentage

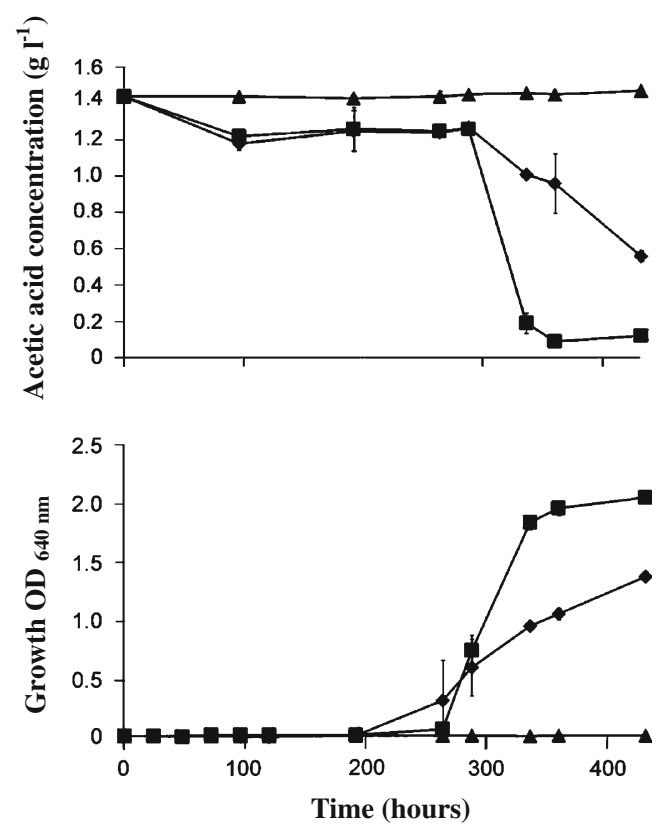

Fig. 2 Growth (OD $640 \mathrm{~nm}$ ) of the S. cerevisiae strain S26 and acetic acid consumption $\left(\mathrm{g} \mathrm{l}^{-1}\right)$ under aerobic (squares), limited-aerobic (diamonds), and anaerobic conditions (triangles) when cultivated in wine 3 (see Table 1) with ethanol $10.4 \%(v / v)$, a volatile acidity of $1.44 \mathrm{~g} \mathrm{l}^{-1}$ (see wine 3 in Table 1 ), at $25^{\circ} \mathrm{C}$ and $\mathrm{pH} 3.55$ of acetic acid reduction (61.5\%) and the decrease in the alcoholic degree (1.4) achieved were lower (Table 6).

\section{Discussion}

From a set of 135 yeast isolates, four strains revealed ability to use glucose and acetic acid simultaneously. Three of the four isolated strains were identified as $S$. cerevisiae species and one as L. thermotolerans. The commercial wine strains S. cerevisiae S26, S29, and S30 also revealed ability to degrade glucose and acetic acid simultaneously. These three strains together with the isolated $S$. cerevisiae strains $43 \mathrm{C}$ and $45 \mathrm{C}$ and $L$. thermotolerans strain $44 \mathrm{C}$ were further assessed regarding their ability to use acetic acid in refermentation assays with media containing acidic wines.

The isolated strain $L$. thermotolerans $44 \mathrm{C}$ displays a behavior similar $(P>0.05)$ to the reference strain $Z$. bailii ISA 1307 both regarding acetic acid and glucose degradation in the presence of high glucose and low ethanol concentrations, under aerobic conditions. L. thermotolerans

Table 6 Consumption of acetic acid in wine by $S$. cerevisiae strain S26, under aerobic, limited-aerobic, and anaerobic conditions, after $432 \mathrm{~h}$

\begin{tabular}{lcc}
\hline Aeration conditions & $\begin{array}{l}\text { Final ethanol } \\
\text { degree } \%(\mathrm{v} / \mathrm{v})\end{array}$ & $\begin{array}{l}\text { Final volatile } \\
\text { acidity g 1 }\end{array}$ \\
\hline Aerobic & $6.5 \pm 0.21$ & $0.12 \pm 0.04$ \\
Limited-aerobic & $9.0 \pm 0.28$ & $0.56 \pm 0.06$ \\
Anaerobic & $8.6 \pm 0.14$ & $1.47 \pm 0.00$ \\
\hline
\end{tabular}

The initial alcoholic degree of the wine was $10.4 \%(v / v)$; the initial volatile acidity was $1.44 \mathrm{~g} \mathrm{l}^{-1}$ (see wine 3 in Table 1 ) 
has been used for wine production as active dry yeast in combination with $T$. delbrueckii and $S$. cerevisiae for enhancing the aroma and flavor of wine (Hansen et al. 2001). Under such conditions, S. cerevisiae strains display highly significant differences $(P<0.001)$ when compared to the same reference strain. Better performance of $L$. thermotolerans regarding acetic acid degradation, comparatively with the $S$. cerevisiae strains, is lost under limitedaerobic conditions. This fact is consistent with the lesser tolerance of $L$. thermotolerans to low oxygen availability than $S$. cerevisiae strains as described by Hansen et al. (2001). On the other hand, in a medium containing low glucose $(3.3 \% w / v)$ and high ethanol $(10 \% v / v)$ under aerobic conditions, S26 is the most efficient acid-degrading strain $(P<0.001)$. These results suggest that under aerobic conditions $S$. cerevisiae strains are less affected by the higher ethanol concentration. However, in a refermentation process with low oxygen availability, and in a medium containing high glucose $(13 \% \mathrm{w} / \mathrm{v})$ and low ethanol $(4 \% \mathrm{v} / \mathrm{v})$ initial concentrations, the $S$. cerevisiae strain S29 is the most efficient strain. Under these same limited-aerobic conditions but in a medium containing initial low glucose $(3.3 \% w / v)$ and high ethanol $(10 \% v / v)$, all $S$. cerevisiae strains studied display acetic acid degradation efficiencies identical to Z. bailii ISA 1307. Therefore, our data show that $S$. cerevisiae strains, under limited-aerobic conditions, can be more or equally efficient as Z. bailii ISA 1307 regarding acetic acid consumption.

Taking into account that the limited-aerobic conditions are more realistic from the perspective of future enological implementation and considering that $Z$. bailii is undesirable for enological applications, our data show that $S$. cerevisiae strains tested can be used to decrease in about $80 \%$ and $40 \%$ of the volatile acidity of an acidic wine containing culture medium under limited-aerobic conditions both for high glucose-low ethanol and low glucose-high ethanol concentrations, after $72 \mathrm{~h}$, respectively. Therefore, the $S$. cerevisiae strains characterized are capable of removing acetic acid independently of the relative amounts of glucose and ethanol. These findings are important from an applied point of view because the strains appear versatile and can be applied in less restrictive conditions regarding glucoseethanol concentrations. At the same time, we find out that $S$. cerevisiae can decrease volatile acidity of wines with an elevated content of acetic acid $\left(1.44 \mathrm{~g} \mathrm{l}^{-1}\right)$ and low residual sugar (1.1 $\mathrm{g} \mathrm{l}^{-1}$, see Table 1), even without further sugar addition, in conditions where oxygen is limited (strain S26).

In this line, the selected $S$. cerevisiae strains will efficiently conduct a refermentation process for volatile acidity reduction. Although it was generally accepted that $S$. cerevisiae strains were unable to consume acetic acid in the presence of glucose, the results obtained show physiological diversity among strains of this species, validating our initial purpose to search for interesting strains among indigenous and commercial yeasts. It is noteworthy that the acetic acid removal efficiencies were obtained for initial concentrations about twofold higher $\left(1.1 \mathrm{~g} \mathrm{l}^{-1}\right)$ than the values proposed for a typical refermentation assay $\left(0.6 \mathrm{~g} \mathrm{l}^{-1}\right)$. It can be therefore anticipated that, in a refermentation process in industrial settings, the desired acetic acid reduction occurs in less than $72 \mathrm{~h}$ and the respective experiments are now underway.

Acknowledgements This study was supported by the program POCI 2010 (FEDER/FCT, POCI/AGR/56102/2004, Fundação para a Ciência e Tecnologia).

Work conducted in Dra. Arlete Mendes Faia laboratory was funded by CGB-IBB and by the project PTDC/AGRALI/71460/2006, Fundação para a Ciência e Tecnologia.

\section{References}

Altschul SF, Gish W, Miller W, Myers EW, Lipman DJ (1990) Basic local alignment search tool. J Mol Biol 215:403-410

Arneborg N, Jespersen L, Jakobsen M (2000) Individual cells of Saccharomyces cerevisiae and Zygosaccharomyces bailii exhibit different short-term intracellular $\mathrm{pH}$ responses to acetic acid. Arch Microbiol 174(1-2):125-128

Boulton RB, Singleton VL, Bisson LF, Kunkee RE (1998) Yeasts and biochemistry of ethanol fermentation, principles and practices of winemaking, 1st edn. Springer, New York, pp 102-192

Casal M, Leão C (1995) Utilization of short-chain monocarboxylic acids by the yeast Torulaspora delbrueckii: specificity of the transport systems and their regulation. Biochim Biophys Acta 1267:122-130

Casal M, Cardoso H, Leão C (1998) Effects of ethanol and other alkanols on transport of acetic acid in Saccharomyces cerevisiae. Appl Environ Microbiol 64(2):665-668

Dos Santos MM, Gombert AK, Christensen B, Olsson L, Nielsen J (2003) Identification of in vivo enzyme activities in the cometabolism of glucose and acetate by Saccharomyces cerevisiae by using ${ }^{13} \mathrm{C}$-labeled substrates. Eukaryot Cell 2(3):599-608

$\mathrm{Du}$ Toit W (2002) Winemaking with rotten grapes: It can be a headache. Wynboer, a technical guide for wine producers. http:// www.wynboer.co.za/recentarticles/1202rotten.php3. Accessed 7 June 2007

Englinton JM, Heinrich AJ, Pollnitz AP, Langridge P, Henschke, PA, Lopes MB (2002) Decreasing acetic acid accumulation by a glycerol overproducing strain of Saccharomyces cerevisiae by deleting the ALD6 aldehyde dehydrogenase gene. Yeast 19(4):295-301

Gerós H, Cássio F, Leão C (2000) Utilization and transport of acetic acid in Dekkera anomala and their implications on the survival of the yeast in acidic environments. J Food Prot 63:96-101

Hansen HE, Nissen P, Sommer P, Nielsen JC, Arneborg N (2001) The effect of oxygen on the survival of non-Saccharomyces yeasts during mixed culture fermentations of grape juice with Saccharomyces cerevisiae. J Appl Microbiol 91:541-547

Jost P, Piendl A (1975) Technological influences on the formation of acetate during fermentation. J Am Soc Brew Chem 34:31-37

Kurtzman CP (2003) Phylogenetic circumscription of Saccharomyces, Kluyveromyces and other members of the Saccharomycetaceae, and the proposal of the new genera Lachancea, Nakaseomyces, Naumovia, Vanderwaltozyma and Zygotorulaspora. FEMS Yeast Res 4(3):233-224 
Kurtzman CP, Robnett CJ (2003) Phylogenetic relationships among yeasts of the 'Saccharomyces complex' determined from multigene sequence analyses. FEMS Yeast Res 3(4):417-432

Lachance MA (1998) The genus Kluyveromyces. In: Kurtzman CP, Fell JW (eds) The yeasts, a taxonomic study. 4th edn. Elsevier, Amsterdam, pp 230-250

Leão C, Van Uden N (1986) Transport of lactate and other short-chain monocarboxylates in the yeast Candida utilis. Appl Microbiol Biotechnol 23:389-393

Lopez V, Querol A, Ramon D, Fernandez-Espinar MT (2001) A simplified procedure to analyse mitochondrial DNA from industrial yeasts. Int J Food Microbiol 68(1-2):75-81

Mohammad JT, Niklasson C, Liden G (1997) Acetic acid friend or foe in anaerobic batch conversion of glucose to ethanol by Saccharomyces cerevisiae? Chem Eng Science 52(15):26532659

O'Donnell K (1993) "Fusarium and its near relatives". In: Reynolds DR, Taylor JW (eds) The fungal holomorph: mitotic, meiotic and pleomorphic speciation in fungal systematics. CABI, Wallingford, pp 225-233

Pérez MA, Gallego FJ, Martinez I, Hidalgo P (2001) Detection, distribution and selection of microsatellites (SSRs) in the genome of the yeast Saccharomyces cerevisiae as molecular markers. Lett Appl Microbiol 33(6):461-466

Remize F, Roustan JL, Sablayrolles JM, Barre P, Dequin S (1999) Glycerol overproduction by engineered Saccharomyces cerevisiae wine yeast strains leads to substantial changes in by-product formation and stimulation of fermentation rate in stationary phase. Appl Environ Microbiol 65:143-149

Remize F, Andrieu E, Dequin S (2000) Engineering of the pyruvate dehydrogenase bypass in Saccharomyces cerevisiae: role of the cytosolic $\mathrm{Mg}^{+}$and mitochondrial $\mathrm{K}^{+}$acetaldehyde dehydrogenases Ald $6 p$ and Ald $4 p$ in acetate formation during alcoholic fermentation. Appl Environ Microbiol 66(8):3151-3159

Ribéreau-Gayon P, Dubourdieu D, Donèche B, Lonvaud A (2000) The microbiology of wine and vinifications. Handbook of enology, vol. 1, 1st edn. Wiley, Chichester

Rodrigues F (1998) Estudos sobre a Regulação do Metabolismo Intracelular de Ácido Acético na Levedura Zygosaccharomyces bailli ISA 1307. Tese de Mestrado, Universidade do Minho, Braga

Saint-Prix F, Bönquist L, Dequin S (2004) Functional analysis of the $A L D$ gene family of Saccharomyces cerevisiae during anaerobic growth on glucose: the NADP +-dependent Ald6p and Ald5p isoforms play a major role in acetate formation. Microbiology 150:2209-2220

Sousa MJ, Rodrigues F, Côrte-Real M, Leão C (1998) Mechanisms underlying the transport and intracellular metabolism of acetic acid in the presence of glucose in the yeast Zygosaccharomyces bailii. Microbiology 144:665-670

Schüller HJ (2003) Transcriptional control of nonfermentative metabolism in the yeast Saccharomyces cerevisiae. Curr Genet 43(3):139-160

Schuller D, Côrte-Real M, Leão C (2000) A differential medium for the enumeration of the spoilage yeast Zygosaccharomyces bailii in wine. J Food Prot 63(11):1570-1575

Schuller D, Valero E, Dequin S, Casal M (2004) Survey of molecular methods for the typing of wine yeast strains. FEMS Microbiol Lett 231(1):19-26

Van Uden N (1967) Transport-limited fermentation and growth of Saccharomyces cerevisiae and its competitive inhibition. Arch Mikrobiol 58:155-168 